\title{
Analysis on Cost Repetitive Control Model of Coal Enterprise
}

\author{
Zhu Meng ${ }^{1, \text { a }}$ \\ ${ }^{1}$ College of resources and safety engineering, China University of Mining and Technology (Beijing), \\ Beijing 100083, China \\ ameng880730@sina.com
}

Keywords: coal enterprise, repetitive control, model, cost

\begin{abstract}
. as for cost management of coal enterprise, this paper puts forward new method of repetitive control design based on 2-D mixed model, it makes research on breakeven repetitive control design and optimization problem with feedback effect. It constructs model suitable for cost evaluation of coal enterprise and applies it into the actual coal enterprise to demonstrate the feasibility of this evaluation model and evaluate cost management level of this coal enterprise, the test result indicates that model is reliable, correct and feasible.
\end{abstract}

\section{Introduction}

With the establishment and improvement of socialist market economic system in China, economic growth way tends to develop towards direction of intensive industry day by day, as the basic resources enterprise, coal enterprise ${ }^{[1,2,3]}$ has started seeking for organic unification such as economic benefits, social benefits and ecological benefits in enterprise. Consideration, analysis and research on structure of manufacturing data cost, social cost and environmental management cost etc have become to be problems that need to be solved at present. As the pillar industry of national economy, coal enterprise has caused a series of environmental problems such as environmental pollution and ecological unbalance etc at the same time of making huge contributions to economic development in China, which not only affects the sustained development of national economy, but also accelerates burden for coal enterprise, enabling environment cost to have more and more percentage in cost fees for coal enterprise.

Repetitive control is one kind of new control method ${ }^{[4,5]}$ that is proposed by Japanese scholar Nakano etc in the 1980s. It is based on internal model principle and plants dynamic model of periodic signal into controller, so that it achieves target ${ }^{[6]}$ of making high-precision tracing on periodic reference input or making effective restriction on periodic interference signal. However, because of time-delay characteristic in repetitive controller, the stability of repetitive control system can not get guarantee ${ }^{[4]}$. In fact, there are 2 completely different actions in repetitive control system: the continuous control action in one period and discrete learning action in every action. By combing with discussion on occurrence characteristic and influence factor in coal enterprise, this paper puts forward new design method of one breakeven repetitive control based on 2-D mixed model on the basis of cost management state, existing problems in coal enterprise. It applies multi-level fuzzy comprehensive evaluation theory and establishes achievement evaluation system of cost management for coal enterprise. In addition, it makes comprehensive analysis on it according to production characteristic of coal enterprise and confirms the quantitative index of cost influence factors for coal enterprise and establishes its cost evaluation index system.

Repetitive control design based on optimal breakeven

As it is indicated by diagram 1, it is the uninvolved cost repetitive structure model. As for uncertain linear system(1) and performance index(2), if it has one positive number $J^{*}$ and repetitive control rule $u^{*}(t)$, which weakens trace error in closed-loop system and performance index meets $J \leq J^{*}$, then $J^{*}$ is regarded as one upper bound of uncertain linear system(3), so it regards $u^{*}(t)$ as one breakeven repetitive control rule of uncertain linear system(3). 


$$
\begin{gathered}
\left\{\begin{array}{l}
\dot{x}(t)=(A+\Delta A) x(t)+(B+\Delta B) u(t) \\
y(t)=C x(t)+D u(t) .
\end{array}\right. \\
\left.J=\int_{0}^{\infty} u(t-L(t)-x(t-L)]^{T} Q_{1}[x(t)-x(t-L)]+[u(t)-u(t-L)\}^{T} R[u(t)-L) Q_{2} e(t-L)\right\} d t
\end{gathered}
$$

As for $\Gamma=0$, which is nominal system of uncertain linear system(3), as for $\xi(t)$, when $t<0$, command $\xi(t)=0$, when $t>0$, command $\Delta \xi(t)=x(t)-x(T-L)$, so that:

$$
\begin{gathered}
\Delta \dot{x}(t)=A \Delta x(t)+B \Delta u(t) \\
e(t)-e(T-L)=-C \Delta x(t)-D \Delta u(t)
\end{gathered}
$$

Of which:

$$
\Delta u(t)=F_{e} \Delta v\left(t 0+F_{p} \Delta x(t)=F_{e} e(t)+F_{p} \Delta x(t)\right.
$$

Repetitive control is depends on 2 separated dynamic processes, now it respectively uses 2 variables $\tau$ and $k$ to indicate the independent variable of these 2 dynamic processes,

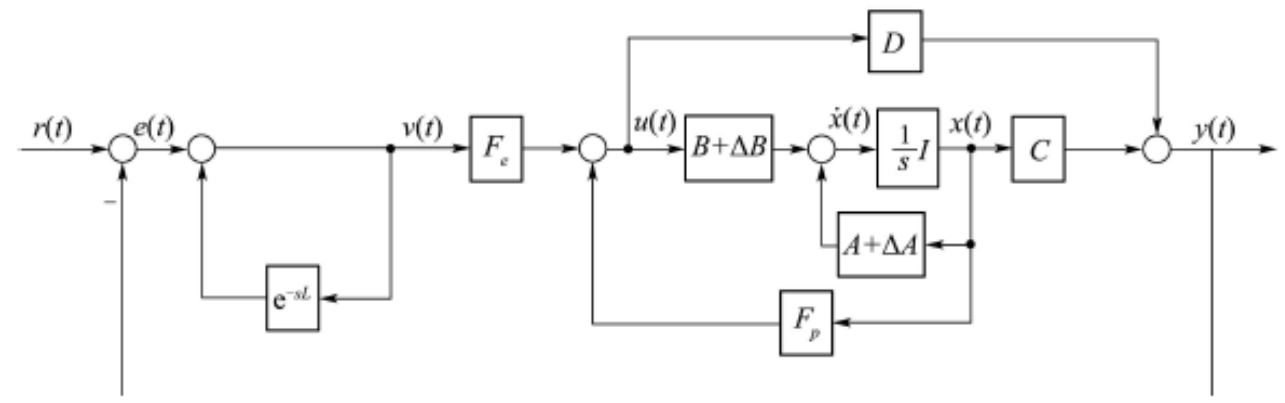

Diagram 1 Structure of repetitive control system

Of which, $\tau$ is the continuous variable of time, $k$ is the discrete variable of learning time, so it further supposes that:

$$
\left\{\begin{array}{l}
\xi(t)=\xi(k L+\tau):=\xi(k, \tau) \\
\xi(t-L)=\xi(k-1)(L+\tau):=\xi(k-1, \tau)
\end{array}\right.
$$

Then formula(5)(6)is converted as follows: :

$$
\begin{gathered}
\Delta \dot{x}(k, \tau)=A \Delta x(k, \tau)+B \Delta u(k, \tau) \quad(7) \\
e(k, \tau)-e(k-1, \tau)=-C \Delta x(k, \tau)-D \Delta u(k, \tau)
\end{gathered}
$$

The control object described by formula (7)(8)is completely different from that by formula (1), formula(1)makes mixed description on continuous control action in one period and discrete learning action in every period, but in description by formula (7) (8), formula(7) describes the continuous control action in the $\mathrm{k}$ period, while formula (8) describes the discrete learning action in the $\mathrm{k}-1$ and $\mathrm{k}$ period. Because formula (9)excludes error item $e(k, \tau)$, so that control action in one period is not affected by learning action, which is conform to fact. On the contrast, from formula (8), we can know that control action in one period will directly affect learning action, which is because the quick weakening on control action, the lower demand of learning.

Learning process is mainly allocated by parameter $\mathrm{Ke}$ (that is $\mathrm{Fe}$ ), control process is mainly allocated by parameter $K p$ (that is $F p$ and $F e$ ), these 2 processes are mutually independent and affected, of which control process can get improvement by regulating $K p$, so that learning process can get improvement by regulating $K e$. The control and learning process in repetitive control system can get separated regulation by feedback gain in feedback controller of 2-D state.

$$
\Delta u(t)=K_{e} e(t-L)+K_{p} \Delta x(t)
$$




\section{Research on improvement of cost accounting system in coal enterprise}

In order to make up for shortages in traditional cost accounting, completely and wholly reflect consumption of coal resources development, this paper integrates the external cost of coal resources into cost management range of coal enterprise, which forms the cost accounting structure of coal enterprise:

$$
C=R_{C}+P_{C}+S_{C}+E_{c}
$$

In the formula: $C$ means cost of coal enterprise; $R_{C}$ means resources cost of coal enterprise; $P_{C}$ manufacturing cost of coal enterprise; $\mathrm{S}_{\mathrm{C}}$ means safety cost of coal enterprise, $\mathrm{E}$ means environmental cost of coal enterprise.

Factors of affecting cost of coal enterprise is very complicated, which not only includes objective factors such as geological conditions etc, but also includes objective factors such as cost management etc, effect of every factor is different. From the cost structure of coal enterprise, influential factor and effect degree are different.

Resources cost of coal enterprise is the related tax cost mainly on mining right price, according to relevant laws and regulations in China, obtaining mining right is the precondition for resources development, while mining right price and tax cost are basically obtained by measurement or charging.

$$
R_{C}=\sum_{i=1}^{n} W_{a i}+\frac{1}{(1+r)^{i-1}}+Q \times T_{R}+Q \times R \times P \times \delta
$$

In the formula: $\mathrm{Wa}_{\mathrm{i}}$ means net profit of coal exploitation; $\mathrm{r}$ means depreciation; I means year number $(\mathrm{i}=1,2,3 \ldots . . \mathrm{n})$; $\mathrm{n}$ means calculation year ; $\mathrm{Q}$ means coal output; T means tax cost of coal resources; R means unit price of coal distribution; $\mathrm{P}$ means compensation cost of coal resources; $\delta$ means resources recovery index.

Factors affecting resources cost of coal enterprise mainly include the following: reserves of coal resources, workable reserves of resources, sales price of coal, production capacity of mine, service time of coal mine, capital market state, tax cost of coal resources, coal resources compensation cost and resources recovery index etc. With the increase of mining recovery, on one hand, exploitation time on limited resources will lengthen and resources recovery will decrease, the mining right price in unit coal resources and coal resources compensation will reduce, but resources tax of unit coal resources will still keep stable, on the other hand, enhancement in resources recovery conforms to encouragement policies in China, which is favorable for reasonable recovery and application of resources and enhancing development efficiency of coal resources. Therefore, enhancement in coal resources recovery is favorable to reduce resources cost of coal enterprise (such as diagram 2).

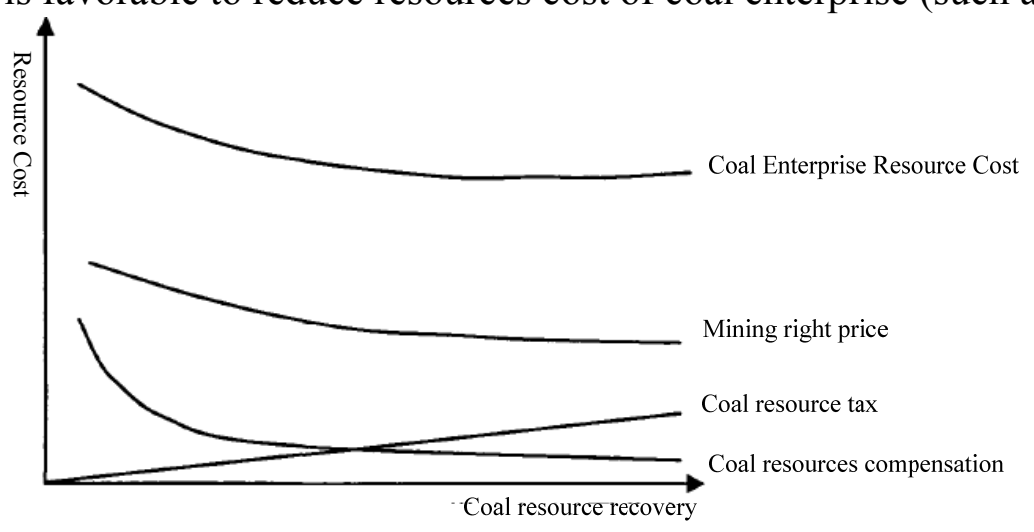

Diagram 2 Relations diagram between coal resources recovery and resources cost of coal enterprise

Activity is the contact bridge for resources and product, the key point and important point of activity cost calculation is activity, activity cost method integrates direct cost into product while divides direct cost into manufacturing cost by quantity motivation and manufacturing cost of non-quantity according to different cost driver. As for manufacturing cost by quantity motivation, 
allocates it into production line by quantity base, while as for manufacturing cost by non-quantity motivation, it makes cost allocation of second stage by basic idea of activity consumption resources and product consumption resources, cost motivation is usually one measurement index for activity consumption. After analyzing and confirming process of cost formation, this paper puts forward the improved cost accounting system (such as diagram 3).
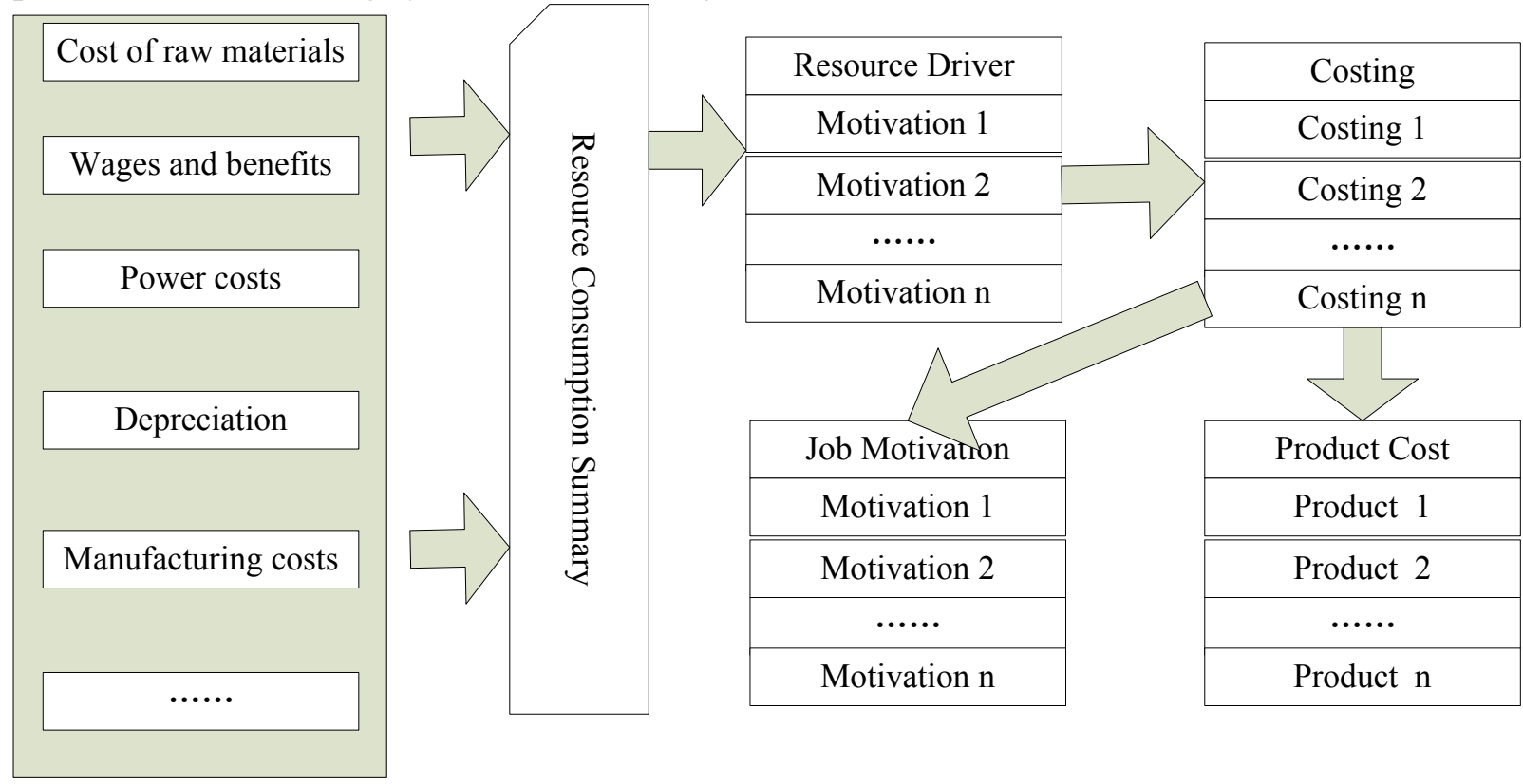

Diagram 3 Cost accounting flow chart after improvement

\section{Establishment on cost evaluation model of coal enterprise}

It needs to determine and measure resources consumption, attribute resources consumption cost into each kind of resources pool. The correct measurement on each kind of resources cost is the base for real accounting cost: confirm activity and resource driver, which reflects consumption way, cause and state of activity on resources, it is the base to allocate resources pool to activity pool, allocates resources cost pool to activity cost pool and confirms activity cost. In the process of cost calculation, each kind of resources pool cost should be allocated to activity cost pool of special range one by one according to its corresponding resources driver. As for the same resources consumed by many activities, it calculates resources distribution rate of each activity according to its resources driver, allocates each resources cost to each activity by distribution rate and forms each kind of activity cost, so that confirms activity cost driver. Activity driver is to allocate activity cost to each kind of product or labor service. After activity driver is confirmed, collect and record activity driver quantity of each kind of product or labor service consumption, calculate cost of activity driver. Cost driver fees means the quantity of manufacturing cost and allocation of cost pool caused by unit cost driver. It makes distribution on cost pool according to cost driver quantity of product consumes each cost pool. The sum on distribution gain of each kind of product from cost pool is the manufacturing cost distribution of each kind of product and then calculates the total cost.

According to analysis on cost influential factors of coal enterprise, we can divide cost evaluation index of coal enterprise into 2 parts, the first part is the production environment of coal enterprise, the second part is the management environment of coal enterprise, and management environment can be subdivided into direct management and indirect management environment, detailed evaluation index. 


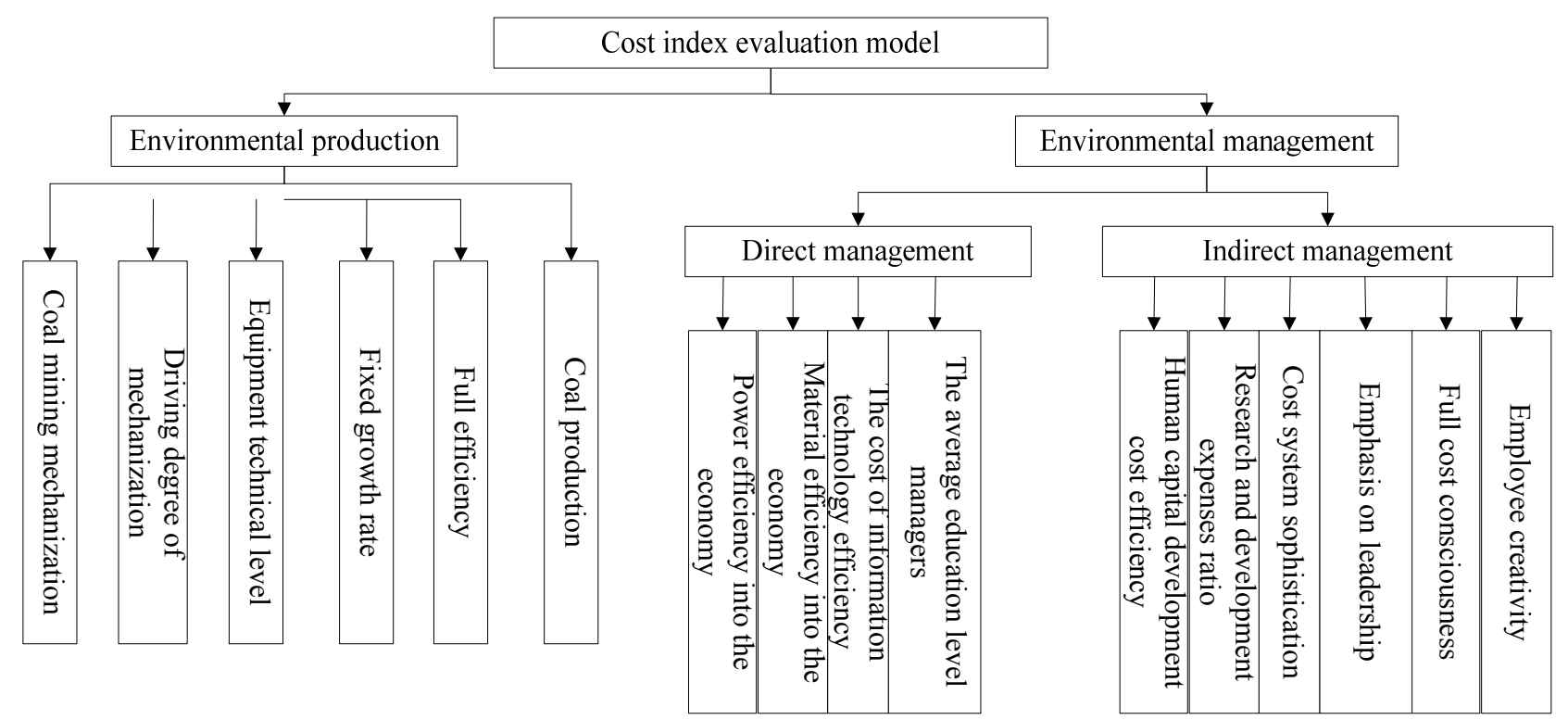

Diagram 4 Cost evaluation index of coal enterprise

Because of many uncertain factors in books purchasing, this paper uses triangular fuzzy membership function to make estimation and evaluation. As for fuzzy subset on real R, it constructs one fuzzy number $\mathrm{H}$, membership function is indicated by formula (12), which indicates triangular fuzzy number $\mathrm{H}_{\mathrm{m}}$ and describes one continuous mapping relationship in range $[0,1]$.

$$
\mathrm{H}_{\mathrm{m}}(\mathrm{x})=\left\{\begin{array}{lc}
\frac{x-c}{a-c} & \mathrm{x} \in[\mathrm{c}, \mathrm{a}] \\
\frac{x-b}{a-b} & \mathrm{x} \in[\mathrm{a}, \mathrm{b}] \\
0 & \text { else }
\end{array}\right.
$$

It establishes index weight matrix according to fuzzy hierarchy process, suppose there are $\mathrm{n}$ index factors, symmetric matrix of $A=\left\{A_{i j}\right\}_{n * n}$, of which, $a_{i j}$ indicates the importance ratio of certain factor $i$ to factor $\mathrm{j}$, its weight standard is indicated by diagram 1 .

Table 1 Index weight standard

\begin{tabular}{cc}
\hline Importance degree of weight factor & Fuzzy measurement grade \\
\hline Factor i and factor $\mathrm{j}$ are of the same & 1 \\
important & 3 \\
Factor is slightly important than factor $\mathrm{j}$ & 5 \\
Factor i is very important than factor $\mathrm{j}$ & 7 \\
Factor is rather important than factor $\mathrm{j}$ & $2,4,6$ \\
Factor i is important than factor $\mathrm{j}$ & \\
\hline
\end{tabular}

After comparative analysis is completed, it makes normalization processing of the above-mentioned matrix. This paper adopts root method to test weight, the detailed calculation is as follows: carry out calculation of $\mathrm{n}$ for root after element product if weight comparison matrix, and it gets weight vector of this evaluation index through normalization processing.

\section{Demonstration analysis on cost evaluation of coal enterprise}

Suppose control object has the following parameters: system simulation result is indicated by diagram 5 . After 2 periods, system output basically enters stable state as for the uncertainty allowed by system, and steady relative error tends to weaken to 0 , system output can better track reference input. 


$$
\left\{\begin{array}{l}
A=\left[\begin{array}{rr}
0 & 1 \\
-1 & -5
\end{array}\right], B=\left[\begin{array}{l}
0.5 \\
0
\end{array}\right] \\
C=\left[\begin{array}{ll}
1 & 0
\end{array}\right], D=2 \\
H_{1}=\left[\begin{array}{ll}
0 & 0 \\
1 & 0.1
\end{array}\right], \Gamma=\left[\begin{array}{ll}
c & 0 \\
0 & c
\end{array}\right], c \in[-1,1] \\
E_{1}=\left[\begin{array}{ll}
1 & 0 \\
0 & 1
\end{array}\right], E_{2}=\left[\begin{array}{l}
0.5 \\
0
\end{array}\right]
\end{array}\right.
$$

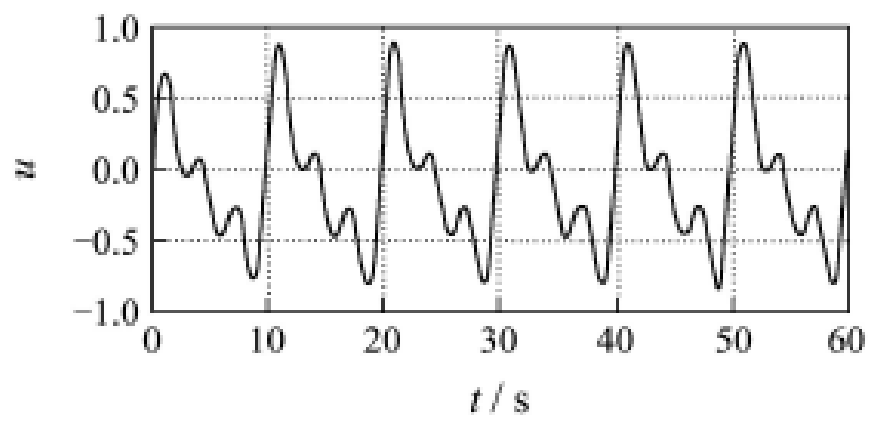

Diagram Simulation result

As it is indicated by table 2, it gets distance between upper idea matrix and bottom idea matrix as well as relative proximity of idea plan.

Table 2 The relative proximity of evaluation and idea plan

\begin{tabular}{cccc}
\hline Relative proximity & $\mathrm{A} 1$ & $\mathrm{~A} 2$ & $\mathrm{~A} 3$ \\
\hline $\begin{array}{c}\text { Production } \\
\text { environment }\end{array}$ & $0 \circ 54$ & $0 \circ 56$ & $0 \circ 56$ \\
$\begin{array}{c}\text { Direct management } \\
\text { environment }\end{array}$ & $0 \circ 65$ & $0 \circ 51$ & $0 \circ 54$ \\
$\begin{array}{c}\text { Indirect management } \\
\text { environment }\end{array}$ & $0 \circ 41$ & $0 \circ 45$ & $0 \circ 46$ \\
\hline
\end{tabular}

It uses principal components analysis method to confirm weight vector of production environment, direct management environment and indirect management environment on total cost management: then $W_{2}=\left(\begin{array}{lll}0.47 & 0.34 & 0.29\end{array}\right)$

$$
A=\left(\begin{array}{lll}
0.47 & 0.34 & 0.29
\end{array}\right)\left[\begin{array}{lll}
0.54 & 0.56 & 0.56 \\
0.65 & 0.51 & 0.54 \\
0.41 & 0.45 & 0.46
\end{array}\right]=\left(\begin{array}{llll}
0.5937 & 0.5671 & 0.5802
\end{array}\right)
$$

From the result by comprehensive evaluation in table 2, we can see that coal enterprise has better cost management level in aspect of production and environmental management, better cost management level in aspect of direct management environment, as well as better cost management in aspect of indirect management environment, which means cost management is maintained on the basis of cost management model.

\section{Summary}

Cost evaluation is the base for operation and decision-making of coal enterprise, in this chapter; it firstly analyzes the influential factors on cost of coal enterprise and confirms the quantitative index of cost evaluation for coal enterprise. Meanwhile, it describes the state of cost evaluation in coal enterprise and constructs cost evaluation model of coal enterprise on this basis, and it applies this model into actual coal enterprise, demonstrates the feasibility of evaluation model and evaluates cost management level of this coal enterprise, finds out the weak point of cost management, which 
provides effective information for enterprise decision maker. This paper introduces 2-D system into repetitive control design for linear continuous and uncertain system of 1-first class; it puts forward breakeven robustness repetitive control design method based on continuous or discrete 2-D mixed model. Introduction of quadratic performance index realizes the independent regulation of learning action and control action in repetitive control as well as enhances trace precision. The existence condition and parameter optimization method of control rule are given by way of linear matrix inequality.

\section{References}

[1] Chang Jianhua, Chen Fugang, Wang Tiezhuang etc.Reserch and Exploration on EconomicContaol Theory of Coal Industry. Beijing: China Broadcasting and Television Press, 2003, p725 -729。

[2] Chen Hongtao, Huang Guoliang. Cost Accounting Frame State and Existing Problem Analysis of Chinese Coal. Coal Economy of Inner Mongolia, Vol 5，2006，p47-50

[3] Duan Zhiping, Yang Shulian. Discussion on Formation Mechanism of Coal Price [J]. Price Theory and Practice, Vol 11, 2002, p21-22.

[4] Xia Xin. Application Research on Work Cost Accounting of Coal Enterprise Based on Management. Journal of Hebei University of Technology, Vol 32，2003， p61一62。

[5] Written by RoberBear, FelixSelunidandRogerMills, Translated by Chen Lianghua, Yang Min. Design on Cost Management-Using Work Model to Establish Cost Control Model, Beijing: China Renmin University Press, 2003, p1-5

[6] Su Ligong. Conception on Improving Accounting Frame of Coal Cost. Research on Coal Economy, Vol 6, 2006, p 4 10

[7] Lv Qiang. Research on Strategic Cost of Coal Enterprise. Master Thesis of Shandong University of Science and Technology, 2003 